\title{
Developmental delays and dental caries in low-income preschoolers in the USA: a pilot cross-sectional study and preliminary explanatory model
}

Donald L Chi , Katharine C Rossitch and Elizabeth M Beeles

\begin{abstract}
Background: Anecdotal evidence suggests that low-income preschoolers with developmental delays are at increased risk for dental caries and poor oral health, but there are no published studies based on empirical data. The purpose of this pilot study was two-fold: to examine the relationship between developmental delays and dental caries in low-income preschoolers and to present a preliminary explanatory model on the determinants of caries for enrollees in Head Start, a U.S. school readiness program for low-income preschool-aged children.

Methods: Data were collected on preschoolers ages 3-5 years at two Head Start centers in Washington, USA $(\mathrm{N}=115$ ). The predictor variable was developmental delay status (no/yes). The outcome variable was the prevalence of decayed, missing, and filled surfaces (dmfs) on primary teeth. We used multiple variable Poisson regression models to test the hypothesis that within a population of low-income preschoolers, those with developmental delays would have increased dmfs prevalence than those without developmental delays.

Results: Seventeen percent of preschoolers had a developmental delay and $51.3 \%$ of preschoolers had $\geq 1 \mathrm{dmfs}$. Preschoolers with developmental delays had a dmfs prevalence ratio that was 1.26 times as high as preschoolers without developmental delays ( $95 \% \mathrm{Cl}: 1.01,1.58 ; \mathrm{P}<.04)$. Other factors associated with increased dmfs prevalence ratios included: not having a dental home $(P=.01)$; low caregiver education $(P<.001)$; and living in a non-fluoridated community $(P<.001)$.

Conclusions: Our pilot data suggest that developmental delays among low-income preschoolers are associated with increased primary tooth dmfs. Additional research is needed to further examine this relationship. Future interventions and policies should focus on caries prevention strategies within settings like Head Start classrooms that serve low-income preschool-aged children with additional targeted home- and community-based interventions for those with developmental delays.
\end{abstract}

\section{Background}

Dental caries is the most common disease in children [1]. Recent epidemiologic data from the U.S. National Health and Nutrition Examination Survey (NHANES) suggest that dental caries prevalence among preschool children ages $2-5$ years increased by $15.1 \%$ (from $24.2 \%$ in $1988-1994$ to $27.9 \%$ in $1999-2004$ ) [2]. Furthermore, from 1999-2004, 47.8\% of preschoolers from low-income households experienced caries and 35\% had untreated

\footnotetext{
* Correspondence: dchi@uw.edu

University of Washington, Box 357475, Seattle 98195, WA, USA
}

caries (compared to $11.4 \%$ and $6 \%$ of preschoolers from higher income households, respectively) [3,4]. These data underscore the association between poverty and poor oral health [5-7] in preschoolers and raise public health concerns, particularly in regards to the U.S. Healthy People 2020 objectives that call for reductions in the percentage of preschoolers with dental caries experience and untreated dental decay to $33.3 \%$ and $23.8 \%$, respectively $[8]$.

Poor oral health is associated with school absenteeism, learning problems, and pain [9] as well as systemic disease, hospitalization, and in rare cases death [10]. Oral diseases

\section{C) Biomed Central}

(C) 2013 Chi et al.; licensee BioMed Central Ltd. This is an open access article distributed under the terms of the Creative Commons Attribution License (http://creativecommons.org/licenses/by/2.0), which permits unrestricted use, distribution, and reproduction in any medium, provided the original work is properly cited. 
during early childhood are likely to have health consequences over the life course [11], which highlights the importance of caries prevention strategies, particularly for low-income preschoolers.

The U.S. Head Start program was promulgated in 1965 to address disparities in school readiness for low-income preschoolers. Head Start emphasizes cognitive and social development as well as health promotion and nutrition [12]. The program focuses on low-income preschoolers and was founded on the premise that improving nutritional intake and health outcomes can help to reduce disparities in school readiness [13]. At the start of each school year, all Head Start enrollees are evaluated by an education specialist to identify special health care needs, which are defined as "deafness, speech or language impairments, visual impairments including blindness, serious emotional disturbance, orthopedic impairments, autism, traumatic brain injury" or developmental delays [12]. For Head Start children identified with a developmental delay, Lead Education Agencies are responsible for providing tailored Individualized Education Programs (IEPs) [14]. IEPs are written documents that describe the child's specific delay, skills that need to be developed, services the school will provide, and where the services will take place. In 2009, there were over 900,000 Head Start enrollees in the U.S. [15] and 12\% of enrollees had an IEP [16].

In regards to dental care, nearly $85 \%$ of Head Start enrollees received preventive dental care and $88 \%$ had a dental examination in the 2010-2011 program year [16]. These data suggest that Head Start has reduced some of the documented barriers to dental care for low-income preschoolers $[17,18]$. However, dental caries prevalence among Head Start enrollees remains high, ranging from $38 \%$ in Connecticut to 86\% in Florida [13-23]. A 2005 prospective study reported that providing dental care coordination services to the caregivers of Head Start enrollees improved dental use for children but did not improve oral health status [24]. Collectively, these findings suggest that interventions focusing solely on increasing dental care utilization are insufficient in preventing dental disease in low-income preschoolers served by the Head Start program.

Targeted interventions, such as school-based sealant programs, have the potential to improve the oral health of children at greatest risk for poor oral health [17]. Anecdotal evidence suggests that preschoolers with developmental delays are at increased risk for dental caries, but there are no published studies to support this hypothesis. The current pilot study was guided by an adapted version of Patrick's sociocultural oral health disparities model [25], which posits that the determinants of dental caries in vulnerable children are multifactorial. We tested two hypotheses: 1) low-income preschoolers with developmental delays have greater dental caries prevalence (measured by $\mathrm{dmfs}$ ) than those without developmental delays; and 2) other factors are associated with dental caries in low-income preschoolers.

\section{Methods}

Study Design, Participants, and Location. This was a cross-sectional pilot study based on secondary data. The study focused on preschoolers ages 3-5 years in two Head Start classrooms in Washington, USA $(\mathrm{N}=115)$. Both classrooms were located in Kittitas County, a rural county in eastern Washington. Over 92\% of Kittitas County is White compared to $82.0 \%$ for Washington state [26]. The median household income was $\$ 42,769$ and $22.3 \%$ of individuals were below the Federal Poverty Level $(\$ 58,890$ and $12.5 \%$, respectively, for Washington state) [26]. We received human subjects approval to conduct this study from the University of Washington Institutional Review Board.

\section{Conceptual model}

A sociocultural model on oral health disparities presented by Patrick and colleagues was adapted to generate a preliminary conceptual model [25]. This model posits that social and cultural factors from multiple levels influence oral health outcomes for vulnerable populations, including low-income preschool-aged children. The original model posits that these multilevel factors interrelate directly and indirectly to produce oral health disparities within vulnerable populations. Our parsimonious model conceptualized covariates as direct correlates of dental caries and each covariate was classified into one of four domains:

Ascribed factors (immutable individual-level demographic characteristics: age, sex, race);

Proximal factors (modifiable individual-level behavioral characteristics: communication difficulties; dental home);

Immediate factors (family-level interpersonal factors: primary caregiver's education; primary caregiver's employment status; family structure; home health environment);

Distal factors (system-level environment: community water fluoridation).

\section{Data sources}

There were two data sources: Head Start enrollment and health history forms. The enrollment form contained demographic information about the child (e.g., age, sex, race, Individual Education Program [IEP] participation) and the primary caregiver (e.g., education, employment, household structure). The health history form contained information on whether the child had difficulties communicating, had a dental home (or a place to take their child for dental care), lived in a smoke-free 
household, and lived in a fluoridated community. All data were from the 2010-2011 Head Start school year.

\section{Outcome measure}

The outcome measure was the number of decayed, missing, or filled surfaces (dmfs) on primary teeth, a composite measure of dental caries and treatment experience. We used the National Institute of Dental and Craniofacial Research (NIDCR) Early Childhood Caries Collaborating Centers (EC4) criteria [27], which are based on the World Health Organization (WHO) methods [28]. The WHO methods define decay on pit and fissure or smooth surfaces as "an unmistakable cavity, undermined enamel, or a detectable softened floor or wall" [28]. To account for trauma and natural exfoliation, a surface was classified as missing only if the tooth was missing because of caries. Surfaces restored with amalgam, composite, glass ionomer, or stainless steel crowns were classified as filled. Sealed surfaces were classified as sound. Consistent with EC4 criteria, if there was uncertainty about the status of a tooth surface, the surface was classified into the more conservative category. Surface-level caries data were collected by a single trained and calibrated pediatric dentist. Five-percent of the study population was randomly selected for a second caries exam to allow for an assessment of intrarater reliability. The Kappa statistic was used to assess for intrarater consistency in the caries data. The intrarater reliability for the caries exam data was found to be Kappa $=0.69$ (95\% CI: 0.61, 0.76; P <.001), which indicates substantial agreement.

\section{Predictor variable}

The main predictor variable was the child's developmental delay status, defined as whether the child had an Individualized Education Program (IEP) (no/yes). While there are limitations associated with using IEP as a proxy for developmental delays (e.g., under-identification of disabilities), nearly $20 \%$ of enrollees in our study had an IEP, which approximates the $12 \%$ of Head Start children nationally with an IEP [16] and the 33\% prevalence estimate of delay from a previous study [29].

\section{Model covariates}

There were 10 model covariates hypothesized as correlates of $\mathrm{dmfs}$ or as confounders of the relationship between developmental delays and $\mathrm{dmfs}$. These covariates were classified into four domains (see Conceptual Model subsection).

There were three ascribed factors that were modeled as confounders: age (3/4/5 years) [30]; sex (female/male) [30]; and race (non-White/White) [31].

There were two binary proximal covariates (no/yes): communication difficulty and dental home. Communication difficulty, assessed by a Head Start teacher, was measured using the communication subsection of the Ages and Stages Questionnaire, 2nd Edition (ASQ). The ASQ is a validated age-specific screener used to assess multiple developmental domains such as communication, motor, problem solving, and personal-social skills [32]. Children scoring greater than 38 points, 39 points, or 31 points on the communication subsection of the 36-, 48-, and 60-month ASQ, respectively, were classified as having no communication difficulties. Remaining children were classified as having communication difficulties. Dental home was assessed by asking the caregiver whether they needed assistance finding a dentist (no/yes) and measured whether the child had a place to go for regular preventive care and restorative dental when needed.

There were four caregiver-reported immediate covariates: caregiver education (less than high school; high school; greater than high school) [30]; caregiver employment status (unemployed; in school/training; employed) [33]; family structure (defined as whether the child lived in a single parent or two parent household) [34]; and whether the child lived in a smoke-free home (no/yes) [35], a proxy for the home health environment.

There was one caregiver-reported distal covariate: whether the child lived in a community with fluoridated water (no/yes) [36].

\section{Statistical analyses}

We did not calculate statistical power based on previous work cautioning against power calculations for retrospective studies [37]. After generating descriptive statistics, we used the Pearson chi-square test to assess the relationships between model covariates and the main predictor variable (developmental delay status) $(\alpha=0.05)$. Because the outcome was not normally distributed, we used the WilcoxonMann-Whitney $U$ test to compare median dmfs rates across model covariates. A multiple variable Poisson regression model was generated to test our hypothesis that the dmfs prevalence rate would be higher in children with developmental delays (GENLIN function with log link). Poisson regression results were presented as regression parameters (i.e., beta coefficients) with standard errors and prevalence ratios. There was no evidence of collinearity between model covariates (e.g., developmental delays and communication difficulties) and all covariates were included in the final regression model. We used PASW Statistics version 18.0 for Windows (Chicago, IL).

\section{Results}

\section{Descriptive statistics}

There were 115 preschoolers in our study and 17.4\% were identified with a developmental delay (Table 1). Thirteen percent of preschoolers had a communication problem and $91.3 \%$ had a dental home. Caregiver education 
Table 1 Pearson Chi-Square test results for bivariate relationships between developmental delay status (Predictor Variable) and model covariates for Head Start children $(\mathrm{N}=115)$

\begin{tabular}{llll}
\hline Variable & $\begin{array}{l}\text { Total study } \\
\text { population }\end{array}$ & $\begin{array}{l}\text { Children with no } \\
\text { developmental delay }\end{array}$ & $\begin{array}{l}\text { Children with } \\
\text { developmental delay } \\
(\mathrm{n}=20)\end{array}$ \\
& $(\mathrm{N}=115)$ & $(\mathrm{n}=95)$ & $\mathrm{n}(\%)$ \\
\hline
\end{tabular}

\section{Ascribed factors}

Age (years)$$
3
$$

4

5

Sex

$$
\begin{aligned}
& \text { Male } \\
& \text { Female }
\end{aligned}
$$

Race

$$
\begin{aligned}
& \text { White } \\
& \text { Non-White }
\end{aligned}
$$

Proximal factors

Communication difficulties

$$
\text { No }
$$$$
\text { Yes }
$$

Dental home

$$
\begin{aligned}
& \text { No } \\
& \text { Yes }
\end{aligned}
$$

\section{Immediate factors}

Caregiver education level

$$
\text { Less than high school }
$$

High school

More than high school

Caregiver employment

$$
\begin{aligned}
& \text { Unemployed } \\
& \text { In school or training } \\
& \text { Employed }
\end{aligned}
$$

Family structure

Single parent

Two parents

Child lives in a smoke-free home

$$
\begin{aligned}
& \text { No } \\
& \text { Yes }
\end{aligned}
$$

\section{Macro factor}

Lives in a community with fluoridated water

$$
\begin{aligned}
& \text { No } \\
& \text { Yes }
\end{aligned}
$$

$22(19.1)$

51 (44.3)

42 (36.5)

57 (49.6)

$58(50.4)$

56 (48.7)

59 (51.3)

96 (87.3)

$14(12.7)$

$10(8.7)$

105 (91.3)

37 (32.2)

39 (33.9)

39 (33.9)

$32(27.8)$

$14(12.2)$

$69(60.0)$

46 (40.0)

69 (60.0)

13 (11.4)

101 (88.6)
$2(10.0)$

9 (45.0)

9 (45.0)

42 (44.2)

$53(55.8)$

$43(45.3)$

52 (54.7)

83 (89.2)

$10(10.8)$

$9(9.5)$

$86(90.5)$

30 (31.6)

34 (35.8)

31 (32.6)

$26(27.4)$

11 (11.6)

58 (61.1)

39 (41.1)

56 (58.9)

9 (9.6)

85 (90.4)
$\mathrm{P}=.46$

$20(21.1)$

42 (44.2)

33 (34.7)

$\mathrm{P}=.01$

15 (75.0)

5 (25.0)

$\mathrm{P}=.11$

$13(85.0)$

7 (35.0)

$$
P=.15
$$

13 (76.5)

4 (23.5)

$$
P=.52
$$

1 (5.0)

$19(95.00$

$$
P=.64
$$

7 (35.0)

5 (25.0)

$8(40.0)$

$\mathrm{P}=.86$

$6(30.0)$

3 (15.0)

11 (55.0)

$P=.62$

7 (35.0)

13 (65.0)

$4(20.0)$

$16(80.0)$ level was evenly distributed across the three categories and $27.8 \%$ of caregivers were unemployed. Nearly $90 \%$ of preschoolers lived in a smoke-free home and $64 \%$ lived in communities with fluoridated water. Significantly larger proportions of preschoolers with a developmental delay were male compared to preschoolers without 
a developmental delay ( $75 \%$ and $44.2 \%$, respectively; $\mathrm{P}=.012$ ).

Nearly $49 \%$ of children had zero dmfs (data not shown). The mean dmfs was 5.8 (standard deviation: $11.2 \mathrm{dmfs}$; median: $1.0 \mathrm{dmfs}$; maximum: $65 \mathrm{dmfs}$ ). The mean number of decayed, filled, and missing surfaces was 1.3, 4.0, and 0.5 , respectively. There were no significant differences in the median dmfs rates across all model covariates (Table 2).

\section{Regression models}

The covariate-adjusted Poisson regression model indicated that developmental delays were significantly associated with dmfs (Table 3). Preschoolers with developmental delays had a dmfs prevalence ratio that was 1.26 times as high as children without developmental delays (95\% CI: $1.01,1.58$; $\mathrm{P}<.04)$. Of the 10 remaining model covariates, six covariates across all four model domains were significantly associated with dmfs (age, communication difficulties, dental home, caregiver education level, caregiver unemployment, and living in a community with fluoridated water). Older preschoolers as well as preschoolers with communication difficulties (ascribed and proximal factors, respectively), those with caregivers who finished high school or less (an immediate factor), and children with an unemployed caregiver (also an immediate facto) had increased dmfs prevalence ratio. Preschoolers with a dental home (a proximal factor) and those living in communities with fluoridated water (a macro factor) had significantly decreased dmfs prevalence ratios.

\section{Discussion}

This is the first published study to examine the relationship between developmental delays and dental caries in low-income preschool-aged children. We tested two hypotheses within a population of preschoolers in the Head Start program. The first hypothesis was that the $\mathrm{dmfs}$ prevalence ratio would be higher for Head Start preschoolers with developmental delays than for Head Start preschoolers without. Our findings support this hypothesis. There are no studies to which we can directly compare our results, but there are three potential explanations. First, preschoolers with developmental delays may not cooperate with home care behaviors such as toothbrushing, which leads to plaque accumulation and limited exposure to topical fluorides. Second, preschoolers with developmental delays may be exposed more frequently to fermentable carbohydrates (e.g., medications, sugar sweetened beverages, sweets). Third, caregivers of preschoolers with disabilities may experience higher levels of caregiver stress [38], which could exacerbate the preceding factors that contribute to poor oral health.
Table 2 Wilcoxon-Mann-Whitney $\mathrm{U}$ test results for bivariate relationship between decayed, missing, or filled tooth surfaces (dmfs) (Outcome Measure) and model covariates for Head Start children $(\mathbf{N}=\mathbf{1 1 5})$

\begin{tabular}{lll}
\hline Variable & $\begin{array}{l}\text { Median dmfs } \\
(\mathbf{N}=115)\end{array}$ & P-value \\
\hline Main predictor variable & & $P=.92$ \\
Developmental delay & & \\
No & 1.0 & \\
Yes & 0.5 &
\end{tabular}

\section{Ascribed factors}

Age (years)

$\mathrm{P}=.27$

3

4

5

Sex

Female

Race

$\mathrm{P}=.24$

White

Non-White

Proximal factors

Communication Difficulties

$\mathrm{P}=.47$

No

Yes

Dental home

$P=.30$

No

Yes

Immediate factors

Caregiver education level

$\mathrm{P}=.42$

Less than high school

0.0

High school

2.0

More than high school

0.0

Caregiver employment

Unemployed

$P=.66$

In school or training

Employed

2.0

0.0

Family structure

$\mathrm{P}=.73$

Single parent

0.5

Two parents

1.0

Child lives in a smoke-free home

$\mathrm{P}=.32$

No

1.0

Yes

Macro factor

Lives in a community with fluoridated water

$\mathrm{P}=.32$ 
Table 3 Final multiple variable poisson regression model on dental caries prevalence for Head Start children $(\mathrm{N}=115)$

Variable

Parameter estimate (B) Standard error $95 \% \mathrm{Cl}$

Developmental delay

$\begin{array}{ll}\text { No } & \text { ref } \\ \text { Yes } & 0.23\end{array}$

\section{Ascribed factors}

Age (years)

$\begin{array}{ll}3 & \text { ref } \\ 4 & 0.49 \\ 5 & 1.44 \\ \text { Sex } & \\ \text { Male } & \text { ref } \\ \text { Female } & -0.07 \\ \text { Race } & \\ \text { White } & \text { ref } \\ \text { Non-White } & -0.09\end{array}$

\section{Proximal factors}

Communication difficulties

$$
\text { No }
$$$$
\text { Yes }
$$

Dental home

$$
\text { No }
$$$$
\text { Yes }
$$

\section{Immediate factors}

$$
\begin{aligned}
& \text { Caregiver education level } \\
& \text { Less than high school } \\
& \text { High school } \\
& \text { More than high school } \\
& \text { Caregiver employment } \\
& \text { Unemployed } \\
& \text { In school or training } \\
& \text { Employed } \\
& \text { Family Structure } \\
& \text { Single parent } \\
& \text { Two parents }
\end{aligned}
$$

Child's lives in a smoke-free home

$$
\begin{aligned}
& \text { No } \\
& \text { Yes }
\end{aligned}
$$

Macro factor

Lives in a community with fluoridated water

$$
\text { No }
$$$$
\text { Yes }
$$
ef
0.49

1.44

ref

$-0.07$

ref

$-0.09$

ref

0.91

ref

$-0.49$

0.95
0.86
ref
ref
0.32
-0.83
ref
0.06
ref
-0.07

0.12
0.15

0.15

0.09

0.11
Prevalence ratio (PR) $\quad 95 \% \mathrm{C}$

P-value

$\mathrm{P}=.04$

$0.01,0.46 \quad 1.26$

$1.01,1.58$ 
not having a dental home, lower caregiver education, unemployment, and living in a community with nonfluoridated water. Previous studies support our findings regarding age [27]. In terms of the significant proximal factors (communication difficulties and dental home) there are no studies to which we can directly compare our findings. However, two studies suggest a relationship between child temperament and caries $[39,40]$. In our study, there was low correlation between communication difficulties and developmental delays, suggesting that these measures capture different aspects of child behaviors. Additional research is needed to identify the mechanisms by which communication difficulties can lead to increased caries. Furthermore, in regards to the dental home variable, a preliminary study reported that young children have less tooth decay when their mothers have a dental home [41]. Our findings are the first to suggest an association between children having a dental home and lower caries experience rates. While dental homes are considered to be important by parents and dentists $[42,43]$, there are few relevant studies to which we can compare our findings. Children with a dental home may have caregivers with good oral health behaviors (e.g., prevention-oriented dental care use, healthy eating, regular home oral hygiene). We recognize the limitations associated with our operationalization of the dental home, which is an area of dental research that requires additional attention. Future research should continue to test different operationalizations of the dental home concept, evaluate clinical outcomes associated with dental homes, and identify the specific features of dental homes that lead to good oral health.

There were also two significant immediate factors: caregiver education level and employment status. There is extensive literature on the oral health effects of low caregiver education, which is associated with low health literacy, negative oral health-related behaviors, and social disadvantage [44-47]. In terms of employment effects, compared to preschoolers with an unemployed caregiver, preschoolers with an employed caregiver had significantly fewer caries whereas preschoolers with a caregiver in school had significantly greater caries. A potential explanation is that employed caregivers may have greater flexibility to take time off from work to take their child to the dentist. Caregivers in school may rely on relatives for caretaking responsibilities, leaving them fewer opportunities to oversee enforcement of toothbrushing and healthy eating. Our findings conflict with a recent study from Australia, which reported no relationship between employment and caries in 20-month old children but reported a significant interaction between employment and family structure [33]. Broadly, there is growing recognition that addressing the social determinants of pediatric health such as caregiver education and employment, has the potential to improve various health outcomes, including oral health [48]. Our findings underscore the importance of identifying the specific factors associated with employment that could promote child health outcomes such as time-flexible work policies [49] and examining how children's oral health is influenced by interactions between employment and family-level factors. Dental health professionals also have a responsibility to partner with the health policy and public health communities to help craft social and economic policies that seek to improve the upstream determinants of health as a way to achieve oral health equity in vulnerable populations.

The only macro factor in our model (living in a community with fluoridated water) was significantly associated with fewer caries. There are numerous studies that support the benefits associated community water fluoridation $[36,50,51]$. Because segments of the population are concerned with the safety of or oppose community water fluoridation [52], there is a need for continued research on the behavioral and social determinants of opposition to water fluoridation. Policies and interventions must be developed to ensure that health professionals have the resources to inform patients and the public about the importance of community water fluoridation.

Also of interest are the two immediate factors (family structure and living in a smoke-free home) and the two ascribed factors (sex and race) that failed to reach statistical significance in our regression model. Our finding that family structure was not associated with caries is inconsistent with a previous study reporting that children from one-parent families had significantly higher caries rates than those from two-parent families [34]. Our results are also inconsistent with previous studies that link caregiver smoking and caries [35,53-55]. One potential explanation is social desirability bias regarding reliable reporting of smoking status [56]. We would not expect differences in dental caries prevalence by sex, as demonstrated in our model, but a previous study found that female infants had greater odds of developing severe caries [31]. Furthermore, in our model, race failed to reach statistical significance, which is inconsistent with previous findings [57]. A possible explanation is low variance in regards to non-White children in our study population, most of whom were of Hispanic or Latino descent. Future research should continue to examine how features associated with households, home health environment, and race/ethnicity are related to dental disease in young children.

Collectively, our findings support a preliminary conceptual model on dental caries for low-income preschoolers enrolled in the Head Start program (Figure 1). There are two features of this model. The first is that the correlates of primary tooth dmfs are found at multiple levels. Our model suggests that reducing dental caries in low-income preschool-aged populations requires complex interventions 
that reach beyond single-level approaches such as ensuring dental homes or community water fluoridation [58]. Limited financial and human resources coupled with persisting caries prevalence rates among vulnerable populations indicate the need for innovative strategies that address the multilevel determinants of poor oral health. This is related to the second feature of the model - the mutability of model covariates. Some of the model features (e.g., developmental delays, caregiver education level, employment) are immutable in the short-term, which represents opportunities to implement targeted interventions and policies. For instance, if children with developmental delays are at greater risk for dmfs, as demonstrated in our study, targeted interventions should focus on these preschoolers rather than all Head Start enrollees. Other model features (e.g., dental home, community water fluoridation) are mutable and may serve as active ingredients in a targeted intervention. For example, an intervention focusing on children with developmental delays could include case managers who work with caregivers and community dentists to ensure that the child is seen regularly by a dentist for checkups and treatment as necessary and behavioral interventions that reinforce use of fluoridated water, regular toothbrushing with fluoride toothpaste, and healthy diet. Additional research is needed to refine and validate our preliminary dental caries model so that appropriate interventions and policies can be developed and tested.

Increases in dental caries prevalence in preschool-aged children in the U.S. have renewed interest in populationbased strategies to prevent and manage dental disease in young children [59]. Intensive multilevel interventions implemented within Head Start classrooms coupled with community- and home-based strategies for the highest risk children may be needed to achieve meaningful health improvements [60]. Head Start programs should implement and test preventive strategies within classrooms (e.g., twice daily toothbrushing with fluoridated toothpaste, diet control, iodine and fluoride varnish applications) $[61,62]$. A recent study conducted within Head Start classrooms suggests that fluoride-xylitol toothpastes are not more efficacious than fluorideonly toothpastes [63]. Research is needed to evaluate the efficacy and acceptability of additional preventive strategies that could be implemented within Head Start classrooms such as toothbrushing with higher concentration fluoride products and distributing snacks containing therapeutic levels of xylitol $[64,65]$. Head Start teachers and caregivers will require training about dental disease prevention and how to properly implement these strategies [66-68]. Beyond the classroom setting, there are promising opportunities to implement caregiver-, household-, and community-level interventions that target Head Start enrollees with developmental delays $[69,70]$. These efforts will require rigorous evaluation so that interventions can be modified as needed and disseminated to other settings.

This study has a number of strengths including adaptation of a conceptual framework that guided all stages of the study, assessment of intrarater reliability for the clinical caries data, and blinding of the caries examiner. However, as with all studies, there were limitations. The first is that our conceptual model is likely to be incomplete. Because of data limitations, we were unable to include all cultural, social, and environmental factors from Patrick's model (e.g., cultural attitudes toward oral health, norms, social capital, social disadvantage, arealevel poverty). Future work could investigate additional cultural and biopsychosocial factors related to dental caries in young children [71]. Second, the data were

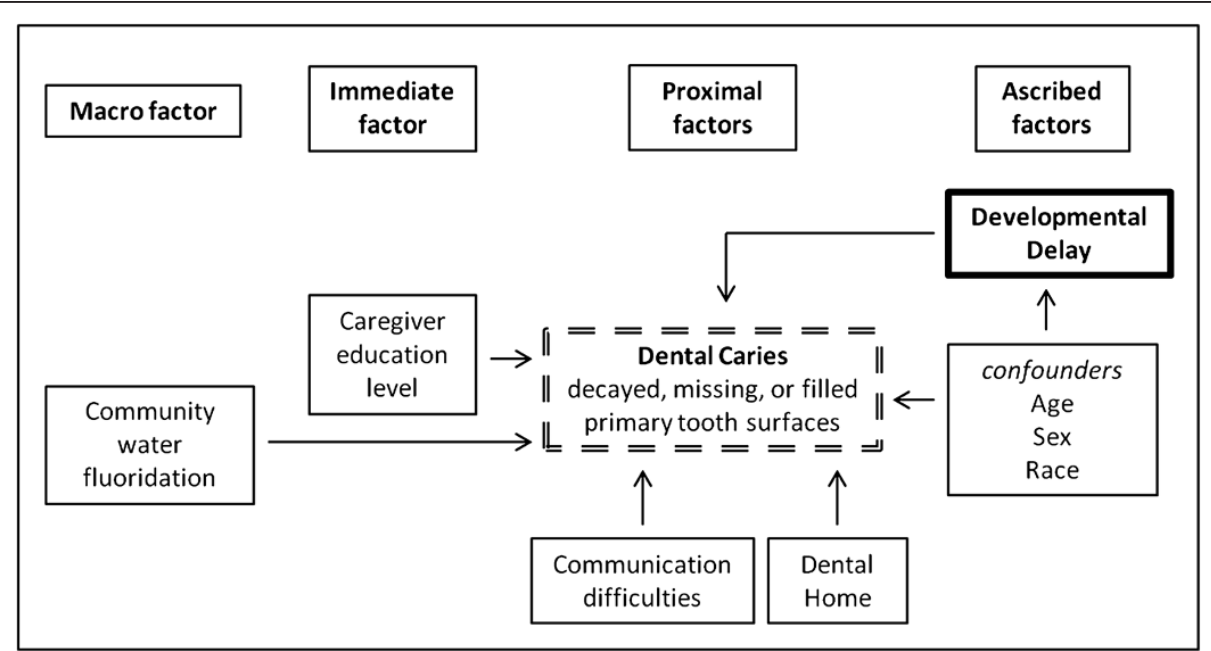

Figure 1 Sample figure title. Preliminary conceptual model on the multilevel factors associated with dental caries experience in Head Start children in the U.S. 
cross-sectional and there is no assumption of causality. Longitudinal studies are needed to better understand how risk factors influence oral health outcomes overtime. Third, the study focused on two Head Start classrooms in a rural county, which limits external generalizability of our study findings. There is a need to conduct larger studies that include Head Start classrooms from a variety of geographic settings.

\section{Conclusions}

Based on the results of this pilot study, we draw two conclusions. There was a significant positive association between developmental delays and dmfs prevalence in low-income preschool-aged children served by Head Start. In addition, factors such as having a dental home and living in a community with fluoridated water were associated with significantly lower $\mathrm{dmfs}$ prevalence ratios. Additional studies are needed to further examine the relationship between developmental delays and primary tooth caries in preschoolers, the mechanisms underlying this relationship, and multilevel strategies to reduce oral health disparities in vulnerable preschool-aged children.

\section{Competing interests}

The authors declared that they have no competing interests.

\section{Authors' contributions}

DLC conceptualized the study, led the data collection, oversaw data analyses, and led in writing the initial and final manuscript. KCR helped to collect and manage data, helped with the data analyses, and assisted with writing the initial and final manuscript. EMB helped to college and manage data and helped write the initial and final manuscript. All authors read and approved the final manuscript.

\section{Acknowledgments}

We would like to thank Bright Beginnings for Kittitas County for granting us permission to conduct this study. Thank you to the Head Start families and children for participating and to Dr. Kiet Ly for organizing the dental exams. This study was made possible by funding from the U.S. National Institute of Dental and Craniofacial Research/National Institutes of Health (Grant Number K08DE020856), U.S. National Institute of Minority Health and Health Disparities/National Institutes of Health (Grant Number L60MD003921), the William T. Grant Foundation Scholars Program, and U.S. National Institute of Dental and Craniofacial Research/National Institutes of Health (Grant Number U54DE019346 to the University of Washington Northwest Center to Reduce Oral Health Disparities)

Received: 8 August 2013 Accepted: 8 October 2013

Published: 12 October 2013

\section{References}

1. U.S. Department of Health and Human Services: Oral Health in America: A Report of the Surgeon General. Rockville, MD: US Department of Health and Human Services, National Institute of Dental and Craniofacial Research, National Institute of Health; 2000.

2. Dye BA, Tan S, Smith V, Lewis BG, Barker LK, Thornton-Evans G, Eke PI, Beltrán-Aguilar ED, Horowitz AM, Li CH: Trends in oral health status: United States, 1988-1994 and 1999-2004. Vital Health Stat 2007, 11:1-92

3. Health Indicators Warehouse; 2013. [http://www.healthindicators.gov/ Indicators/Dental-caries-experience-children-3-5-years-percent_1269/Profile/ Data], Archived by WebCite at [http://www.webcitation.org/6liufxcrf]

4. Health Indicators Warehouse; 2013. [http://www.healthindicators.gov/ Indicators/Dental-decay-untreated-children-3-5-years-percent_1272/Profile/ Data], Archived by WebCite at [http://www.webcitation.org/6liv59SwT]
5. Ramos-Gomez FJ, Weintraub JA, Gansky SA, Hoover Cl, Featherstone JD: Bacterial, behavioral and environmental factors associated with early childhood caries. J Clin Pediatr Dent 2002, 26:165-173.

6. Dye BA, Arevalo O, Vargas CM: Trends in paediatric dental caries by poverty status in the United States, 1988-1994 and 1999-2004. Int J Paediatr Dent 2010, 20:132-143.

7. Da Fonseca MA: The effects of poverty on children's development and oral health. Pediatr Dent 2012, 34:32-38.

8. Healthy People 2020 Topics \& Objectives: Oral Health; 2013. [http://www. healthypeople.gov/2020/topicsobjectives2020/objectiveslist.aspx?topicld=32], Archived by WebCite at [http://www.webcitation.org/6livHJY3w]

9. Jackson SL, Vann WF Jr, Kotch JB, Pahel BT, Lee JY: Impact of poor oral health on children's school attendance and performance. Am J Public Health 2011, 101:1900-1906.

10. Casamassimo PS, Thikkurissy S, Edelstein BL, Maiorini E: Beyond the dmft: the human and economic cost of early childhood caries. J Am Dent Assoc 2009, 140:650-657.

11. Nicolau B, Thomson WM, Steele JG, Allison PJ: Life-course epidemiology: concepts and theoretical models and its relevance to chronic oral conditions. Community Dent Oral Epidemiol 2007, 35:241-249.

12. U.S. Department of Health and Human Services Administration for Children \& Families: Office of Head Start; 2013. [http://eclkc.ohs.acf.hhs.gov/hslc/standards/ Head\%20Start\%20Requirements/1308/1308.3\%20Definitions.htm], Archived by WebCite [http://www.webcitation.org/6livbehgp]

13. Fiscella K, Kitzman H: Disparities in academic achievement and health: the intersection of child education and health policy. Pediatrics 2009, 123:1073-1080.

14. U.S. Department of Health and Human Services Administration for Children \& Families: Office of Head Start; 2013. [http://eclkc.ohs.acf.hhs.gov/hslc/ standards/Head\%20Start\%20Requirements/1308/1308.19\%20\%20Developing \%20individualized\%20education\%20programs\%20(IEPs).htm], Archived by WebCite at [http://www.webcitation.org/6livnSZe5]

15. U.S. Department of Health and Human Services Administration for Children \& Families: Office of Head Start; 2013. [http://eclkc.ohs.acf.hhs.gov/hslc/mr/ factsheets/fHeadStartProgr.htm], Archived by WebCite at [http://www. webcitation.org/6livxePb4]

16. U.S. Department of Health and Human Services Administration for Children \& Families: Office of Head Start; 2013. [http://www.acf.hhs.gov/programs/ohs/ quick-fact], Archived by WebCite at [http://www.webcitation.org/6liw7SUxs]

17. Siegal MD, Detty AM: Targeting school-based dental sealant programs: who is at "higher risk"? J Public Health Dent 2010, 70:140-147.

18. Goldberg E, Lewis P, Ferguson F: Oral health status and access-to-care concerns of Suffolk County Head Start children. NY State Dent J 2011, 77:20-22.

19. Vargas CM, Monajemy N, Khurana P, Tinanoff N: Oral health status of preschool children attending Head Start in Maryland, 2000. Pediatr Dent 2002, 24:257-263.

20. Montero MJ, Douglass JM, Mathieu GM: Prevalence of dental caries and enamel defects in Connecticut Head Start children. Pediatr Dent 2003, 25:235-239.

21. Siegal MD, Yeager MS, Davis AM: Oral health status and access to dental care for ohio head start children. Pediatr Dent 2004, 26:519-525.

22. Autio-Gold JT, Tomar SL: Prevalence of noncavitated and cavitated carious lesions in 5-year-old head start schoolchildren in Alachua County, Florida. Pediatr Dent 2005, 27:54-60.

23. Anderson L, Martin NR, Burdick A, Flynn RT, Blaney DD: Oral health status of New Hampshire Head Start children, 2007-2008. J Public Health Dent 2010, 70:245-248.

24. U.S. Department of Health and Human Services Administration for Children \& Families: Head Start Impact Study: First Year Findings; 2005. [http://www.acf.hhs. gov/programs/opre/hs/impact_study/reports/first_yr_finds/first_yr_finds.pdf], Archived by WebCite at [http://www.webcitation.org/6lj26aNY0]

25. Patrick DL, Lee RS, Nucci M, Grembowski D, Jolles CZ, Milgrom P: Reducing oral health disparities: a focus on social and cultural determinants. BMC Oral Health 2006, 15(6 Suppl 1):S4.

26. U.S. Census Bureau: Washington: Kittitas County; 2012. [http://quickfacts. census.gov/qfd/states/53/53037.html], Archived by WebCite at [http://www. webcitation.org/6lij2OdfHV]

27. Warren JJ, Weber-Gasparoni K, Marshall TA, Drake DR, Dehkordi-Vakil F, Dawson DV, Tharp KM: A longitudinal study of dental caries risk among very young low SES children. Community Dent Oral Epidemiol 2009, 37:116-122.

28. World Health Organization: Oral Health Survey, Basic Methods. 4th edition. Geneva, Switzerland: WHO; 1997. 
29. Barton LR, Spiker D, Williamson C: Characterizing disability in Head Start programs: not so clearcut. Early Child Res Q 2012, 27:596-612.

30. Shiboski CH, Gansky SA, Ramos-Gomez F, Ngo L, Isman R, Pollick HF: The association of early childhood caries and race/ethnicity among California preschool children. J Public Health Dent 2003, 63:38-46.

31. Ismail Al, Lim S, Sohn W, Willem JM: Determinants of early childhood caries in low-income African American young children. Pediatr Dent 2008, 30:289-296.

32. Bricker DD, Squires J, Mounts L, Squires J: Ages \& Stages Questionnaires: A Parent-Completed, Child-Monitoring System. 2nd edition. Paul H. Brookes: Baltimore, MD; 1999

33. Plutzer K, Keirse MJ: Influence of first-time mothers' early employment on severe early childhood caries in their child. Int J Pediatr 2012. Epub 2012 Oct 11.

34. Plutzer K, Keirse MJ: Incidence and prevention of early childhood caries in one- and two-parent families. Child Care Health Dev 2011, 37:5-10.

35. Shenkin JD, Broffitt B, Levy SM, Warren JJ: The association between environmental tobacco smoke and primary tooth caries. J Public Health Dent 2004, 64:184-186.

36. Gillcrist JA, Brumley DE, Blackford JU: Community fluoridation status and caries experience in children. J Public Health Dent 2001, 61:168-171.

37. Lenth RV: Statistical power calculations. J Anim Sci 2007, 85:E24-29.

38. Chi DL, McManus BM, Carle AC: Caregiver burden and preventive dental care use for US children with special health care needs: a stratified analysis based on functional limitation. Matern Child Health J 2013. Epub 2013 Jun 23.

39. Quinonez R, Santos RG, Wilson S, Cross H: The relationship between child temperament and early childhood caries. Pediatr Dent 2001, 23:5-10.

40. Spitz AS, Weber-Gasparoni K, Kanellis MJ, Qian F: Child temperament and risk factors for early childhood caries. J Dent Child (Chic) 2006, 73:98-104.

41. Milgrom P, Sutherland M, Shirtcliff RM, Ludwig S, Smolen D: Children's tooth decay in a public health program to encourage low-income pregnant women to utilize dental care. BMC Public Health 2010, 18(10):76.

42. Kagihara LE, Huebner CE, Mouradian WE, Milgrom P, Anderson BA: Parents' perspectives on a dental home for children with special health care needs. Spec Care Dentist 2011, 31:170-177.

43. American Academy of Pediatric Dentistry: Policy on the dental home. Pediatr Dent 2012-2013, 34:24-25.

44. Psoter WJ, Pendrys DG, Morse DE, Zhang H, Mayne ST: Associations of ethnicity/race and socioeconomic status with early childhood caries patterns. J Public Health Dent 2006, 66:23-29.

45. Vann WF Jr, Lee JY, Baker D, Divaris K: Oral health literacy among female caregivers: impact on oral health outcomes in early childhood. $J$ Dent Res 2010, 89:1395-1400.

46. Skeie MS, Espelid I, Riordan PJ, Klock KS: Caries increment in children aged 3-5 years in relation to parents' dental attitudes: Oslo, Norway 2002 to 2004. Community Dent Oral Epidemiol 2008, 36:441-450.

47. Ismail Al, Sohn W, Lim S, Willem JM: Predictors of dental caries progression in primary teeth. J Dent Res 2009, 88:270-275.

48. Commission on Social Determinants of Health: Closing the Gap in a Generation: Health Equity through Action on the Social Determinants of Health. Final Report of the Commission on Social Determinants of Health. Geneva: World Health Organization; 2008.

49. Halpern DF: How time-flexible work policies can reduce stress, improve health, and save money. Stress Health 2005, 21:157-168.

50. McDonagh MS, Whiting PF, Wilson PM, Sutton AJ, Chestnutt I, Cooper J, Misso K, Bradley M, Treasure E, Kleijnen J: Systematic review of water fluoridation. BMJ 2000, 7(321):855-859.

51. Parnell C, Whelton H, O'Mullane D: Water fluoridation. Eur Arch Paediatr Dent 2009, 10:141-148.

52. Armfield JM, Akers HF: Community water fluoridation support and opposition in Australia. Community Dent Health 2011, 28:40-46.

53. Williams SA, Kwan SY, Parsons S: Parental smoking practices and caries experience in pre-school children. Caries Res 2000, 34:117-122.

54. Hanioka T, Nakamura E, Ojima M, Tanaka K, Aoyama H: Dental caries in 3-year-old children and smoking status of parents. Paediatr Perinat Epidemiol 2008, 22:546-550.

55. Tanaka K, Miyake $Y$, Sasaki S: The effect of maternal smoking during pregnancy and postnatal household smoking on dental caries in young children. J Pediatr 2009, 155:410-415.

56. Gorber SC, Schofield-Hurwitz S, Hardt J, Levasseur G, Tremblay M: The accuracy of self-reported smoking: a systematic review of the relationship between selfreported and cotinine-assessed smoking status. Nicotine Tob Res 2009, 11:12-24.
57. Nunn ME, Dietrich T, Singh HK, Henshaw MM, Kressin NR: Prevalence of early childhood caries among very young urban Boston children compared with US children. J Public Health Dent 2009, 69:156-162.

58. Chi DL: Reducing Alaska Native pediatric oral health disparities: a systematic review of oral health interventions and a case study on multilevel strategies to reduce sugar sweetened beverage intake. Int J Circumpolar Health 2013, 72:21066.

59. Milgrom $\mathrm{P}, \mathrm{Chi}$ DL: Prevention-centered caries management strategies during critical periods in early childhood. J Calif Dent Assoc 2011, 39:735-741.

60. Agrawal T, Hoffman JA, Ahl M, Bhaumik U, Healey C, Carter S, Dickerson D, Nethersole S, Griffin D, Castaneda-Sceppa C: Collaborating for impact: a multilevel early childhood obesity prevention initiative. Fam Community Health 2012, 35:192-202.

61. Kanellis MJ: Caries risk assessment and prevention: strategies for Head Start, Early Head Start, and WIC. J Public Health Dent 2000, 60:210-217.

62. Milgrom $P$, Weinstein $P$, Huebner $C$, Graves J, Tut O: Empowering Head Start to improve access to good oral health for children from low income families. Matern Child Health J 2011, 15:876-882.

63. Chi DL, Tut O, Milgrom P: Cluster-randomized xylitol toothpaste trial for early childhood caries prevention. J Dent Child. In Press.

64. Stokes E, Ashcroft A, Burnside G, Mohindra T, Pine CM: Randomised controlled trial of the efficacy of a high-fluoride gel self-applied by toothbrushing in children at high caries risk. Caries Res 2011, 45:475-485.

65. Autio JT, Courts FJ: Acceptance of the xylitol chewing gum regimen by preschool children and teachers in a Head Start program: a pilot study. Pediatr Dent 2001, 23:71-74.

66. Chinn $\mathrm{CH}$ : Effectiveness of an oral health program in improving the knowledge and competencies of head start staff. Pediatr Dent 2011, 33:403-408.

67. Kranz AM, Rozier RG, Zeldin LP, Preisser JS: Oral health activities of early head start teachers directed toward children and parents. J Public Health Dent 2011, 71:161-169.

68. Miller AP, Kameka M, Young-Whiting C: The effects of an oral health intervention on caregivers of Head Start children. J Natl Black Nurses Assoc 2012, 23:52-58.

69. Ismail Al, Ondersma S, Jedele JM, Little RJ, Lepkowski JM: Evaluation of a brief tailored motivational intervention to prevent early childhood caries. Community Dent Oral Epidemiol 2011, 39:433-448.

70. Plonka KA, Pukallus ML, Barnett A, Holcombe TF, Walsh L, Seow WK: A controlled, longitudinal study of home visits compared to telephone contacts to prevent early childhood caries. Int J Paediatr Dent 2013, 23:23-31.

71. Reisine $\mathrm{S}$, Litt M, Tinanoff N: A biopsychosocial model to predict caries in preschool children. Pediatr Dent 1994, 16:413-418.

doi:10.1186/1472-6831-13-53

Cite this article as: Chi et al:: Developmental delays and dental caries in low-income preschoolers in the USA: a pilot cross-sectional study and preliminary explanatory model. BMC Oral Health 2013 13:53.

\section{Submit your next manuscript to BioMed Central and take full advantage of:}

- Convenient online submission

- Thorough peer review

- No space constraints or color figure charges

- Immediate publication on acceptance

- Inclusion in PubMed, CAS, Scopus and Google Scholar

- Research which is freely available for redistribution 